\title{
Article
}

Ali Hasan* and Jennifer Kayle

\section{Unplanned Coordination: Ensemble Improvisation as Collective Action}

\author{
https://doi.org/10.1515/jso-2020-0004
}

Published online August 30, 2021

\begin{abstract}
The characteristic features of ensemble dance improvisation (EDI) make it an interesting case for theories of intentional collective action. These features include the high degree of freedom enjoyed by each individual, and the lack of fixed hierarchical roles, rigid decision procedures, or detailed plans. We present a "reductive" approach to collective action, apply it to EDI, and show how the theory enriches our perspective on this practice. We show, with the help of our theory of collective action, that EDI (as typically practiced) constitutes a significant collective achievement, one that manifests an impressive, spontaneous, jointly cooperative and individually highly autonomous activity that meets demanding aesthetic standards. Its being good in this way is not a mere extrinsic feature of the artwork, but part of its aesthetic value. We end by discussing how this value is easily missed by classic aesthetics, but is revealed by more contemporary frameworks like social aesthetics.
\end{abstract}

Keywords: collective action, collective intentionality, reductive theories of collective action, social aesthetics, dance, improvisation, ensemble improvisation

Consider the following case of doing things together:

Nine women in a long narrow boat are members of a crew team. In unison, eight women pull on the oars at the direction of the coxswain, with the shared intent of being the first boat to cross the finish line.

*Corresponding author: Ali Hasan, Philosophy, University of lowa, lowa City, 52242-1002, lowa, USA, E-mail: ali-hasan@uiowa.edu. https://orcid.org/0000-0003-2963-2573

Jennifer Kayle, Dance, University of lowa, lowa City, lowa, USA

Ә Open Access. (๑) 2021 Ali Hasan and Jennifer Kayle, published by De Gruyter. (cc)BY licensed under the Creative Commons Attribution 4.0 International License. 
This is a clear, indeed, paradigm case of a collective intentional action-“collective action" for short. ${ }^{1}$ Consider another case of doing things together. Suppose you observe the following:

A group of improvising dancers are "warming-up" with their eyes closed. Each dancer seems immersed in a private experience. Ripples of subtle movement permeate the room. Eventually, eyes begin to open, and without external prompting, individuals coalesce into small groups; without verbal communication or overt teaching, they sometimes perform the same movements, as if permeable to each another, absorbing motions like a drop of dye in a glass of water. The groups combine and dissolve by a logic that seems internal to the process. As if by design, some dancers decumulate to the periphery and stop. Others create a comedy of gestures, unpredictably signaling left and right, both leading and following these signals until they are crowded into the corner. The entire room shares a long, quiet stillness that seems to confirm an agreement - this is the end.

What have we just witnessed? Certainly, there is coordination here, and it is not all happening by coincidence. But neither is it scripted. Suppose that the group began with a plan to "warm-up, work together and end in about 30 minutes." There is some sort of group communication, negotiation, and organization happening here, but does it count as a case of collective (intentional) action?

The intuitive answer is: yes. What plausible account of collective action can accommodate this, one that explains why both examples above, and others besides, count as genuine cases of collective action despite their significant differences? What account can make sense of group actions that follow a step-bystep plan, as well as the spontaneous actions of the improvising dancers, both as genuine cases of collective action, without allowing just any aggregate or collection of individual actions to count?

Setting aside the case of ensemble improvisation for a moment, why should we care to understand the nature of collective action or attempt to provide an account of it? First, collective action has practical significance: many important things simply cannot be accomplished without it. Understanding what makes collective action possible, and what could get in the way, could have practical import. Second, on at least some theories, the normative status of an act can be affected by collective participation or its lack. ${ }^{2}$ Consider the act of making a law. A law established by dictator's edict holds an ethical status and authority

1 We might perform actions that, taken together, have some consequences $\mathrm{X}$ that no one could cause on their own, and in this broad sense it would be true that "we collectively brought about X." But we might not have intended to do so.

2 For example, some modern theories of democracy or political legitimacy take some form of collective participation on the part of citizens to be required for legitimacy. See for example, Pateman (1970), Manin (1987), and Pettit (2012). For some discussion of such views, see Peter (2017). 
different than that established through a collective process. Even if the dictator's rule is the very same as that established by a more collective process, it might fail to have the legitimacy of the latter. In other cases, the collective nature of a wrongful act can make it more likely to accomplish its evil ends, as when officers conspire to plant evidence against innocent victims. Third, understanding the nature of collective action is vital for tackling difficult questions about when and how to distribute responsibility amongst participants in a collective act. For these and other reasons, it is valuable to clearly understand collective action and to properly distinguish it from activities that involve multiple individuals but that are not collective actions.

In this article, we consider ensemble dance improvisation (EDI), which may also be called "compositional improvisation"33 or "performance improvisation,"4 as a kind of collective action. ${ }^{5}$ In the arts, the idea of spontaneous co-creation by a group is hardly new or unique to dance. A more common example is that of jazz music. ${ }^{6}$ Like jazz, the practices and performances of dance improvisation might require members of the group to negotiate spontaneous action in relation to what is "scored" or composed in advance. Toward one end of the spectrum, there may be pre-determined movements, tasks, qualities, or themes; dancers work together to manipulate, inflect, or "riff" on a pre-packaged palette of ingredients, or they may alternate between spontaneous choices and prescribed sequences. At the other end of the spectrum, only the approximate duration of the performance is pre-determined; dancers collaborate in a spontaneous structuring process to build a coherent work that is broadly "choreographic." This is not to say that everything is entirely "new." Movement histories and habits, training practices, and shared knowledge influence the process. Practitioners who engage in more open-ended forms view their work as drawing from past influences, bringing the known into a new context, weaving familiar threads into new tapestries. ${ }^{7}$

The characteristic features of EDI make it a complex and interesting case for theories of collective action, especially theories in which the planning by individuals plays a central role. These features include a high degree of individual freedom, a lack of fixed hierarchical roles in the group, and a high degree of indeterminacy throughout, including lack of rigid decision procedures, detailed scripts or plans.

3 Term used by Judy Dunn, see Buckwalter (2010, p. 108).

4 Term used by Penny Campbell, see Buckwalter (2010, p. 49).

5 For relevant discussions in history and theory of EDI, see Buckwalter (2010), Foster (2002), Albright and Gere (2003), Goldman (2010), and Sgorbati, Emily, and Marie (2013).

6 See Clarke and Doffman (2017) for recent essays on collaborative improvisation in music. See also Belgrad (2016), Borgo (2016), and Hagberg (2016).

7 Susan Sgorbati and others, discussed in Buckwalter (2010, pp. 12-31). 
Our primary goals are to present a theory of collective action that is "reductive" (in a specific sense we shall make clear), a theory inspired by the works of Michael Bratman and Kirk Ludwig, apply it to the case of EDI, and show how the theory enriches our perspective on this artistic practice and its aesthetic value. While we do provide some motivation for the theory, noting its parsimony, and showing that it is able accommodate intuitions about which cases count as collective actions, including cases of ensemble improvisation, we do not argue that it is preferable to the alternatives here. Rather, we take it as given and investigate what light it can shed on this case. As we'll see, in light of the reductive theory, EDI, as typically practiced, emerges as a kind of ideal of collective action, one that models important social values as it cultivates and exercises our capacities for both autonomy and cooperation, liberty and community, and as such is praiseworthy as a collective achievement. A core part of its aesthetic value is easily missed by traditional approaches to aesthetics, but not by contemporary approaches (e.g., social aesthetics). The theory also suggests productive questions in pedagogy, training, and practice for those keen to develop the co-creative potential of improvising together.

The article proceeds as follows. We begin by summarizing main approaches to collective action, and motivating the reductive, content approach defended by Bratman (2014) and Ludwig (2016), elaborating on its basic requirement-the weintention condition - in general, and in relation to the case of EDI (Sections 1 and 2). We distinguish between the "whole" of a collective intentional activity and its intentional "parts" (Section 3) and explain how collective intentional actions can accommodate a high degree of uncertainty and spontaneity (Sections 4 and 5). We then discuss improvisation training and how it develops the sorts of skills that support spontaneous ensemble dance making (Section 6). In the final three sections, we elaborate on how ideals of cooperation and respect for individual autonomy are guiding principles of EDI (Section 7), examine what it means to make autonomous choices in this context (Section 8), and explain why these features of EDI are important parts of its value and should inform its aesthetic evaluation (Section 9).

\section{Collective Action and Collective Intentionality}

Any account of collective action must distinguish it from a mere aggregate of individual acts. There is a difference, for example, between a group of people, simultaneously, yet incidentally, running to the rain shelter, and a dance group that does the same in a site-specific performance in the park (Searle 1990, p. 402). Their behavior might be identical, so that is not enough to distinguish the one from the other. The nature of intentions in each group is very different, and this suggests 
that the intention of participants is relevant to whether we have a case of collective action. But having similar intentions is not enough: I might intend to hike on this trail, and so might you (at the same time), and we might even coordinate our walking so as to avoid colliding, but it doesn't follow that we are going on a hike together in the relevant sense. What is missing? It seems that the intended behaviors must coalesce, not by coincidence, nor merely by some external force; the coalescing behaviors must occur because it is something that is, at some level, collectively intended or aimed at.

But what exactly is this shared intentionality that serves to coordinate action? Suppose that we intend to move a piano together. According to group-agent or plural-subject accounts, there is an intention to move the piano, and the subject or agent of the intention is us, the group. On this view, there is an intention that literally attaches to a group subject or group agent (and not merely its members). ${ }^{8}$

A more common approach is to understand collective intentionality in terms of interrelated individual attitudes and intentions, without appeal to a plural or group subject. For example, according to special-mode accounts (e.g., Searle 1990), just as believing that my lottery ticket is a winner and desiring that it is a winner are different kinds of states with similar content or subject matter, my intention that I move the piano and my intention that we move the piano are essentially different kinds of states. In contrast, proponents of content accounts take the relevant difference to be in the content or subject matter of the intentions-what, specifically, the intentions are about-rather than in their mode. For example, according to Bratman and Ludwig, each member of the group must have an intention whose content includes the joint activity; in our example, we must each intend that we move the piano.

Bratman's and Ludwig's content accounts are reductive theories in the sense that they construct their accounts of collective action by using and extending concepts for individual action and individual agency. In contrast, group-agent and special-mode accounts are non-reductive. ${ }^{9}$ As just discussed, the former appeals to an irreducible group agent or plural subject; the latter focuses instead on the mode of intention in an individual's mind, and claims it is a special we-mode that cannot be understood as an I-mode directed at some specific content. It is worth briefly mentioning one theoretical motivation in favor of the reductive view. A central worry often raised for both group-agent and special-mode accounts is that they require introducing a distinct, irreducible special sort of "plural subject" or a special sort of state respectively. There are good reasons to be theoretically

8 See, for example, Gilbert's (1989) discussion of “plural subjects." See also, List and Pettit (2011). 9 One complication that we are ignoring here is that even some content accounts are nonreductive (see Tuomela 2005, 2018). 
parsimonious, other things being equal-to not posit new kinds of subjects or states if we can avoid doing so. Moreover, many find the central irreducible components of each of these accounts mysterious (Alonso 2018; Bratman 2014; Kutz 2000; Ludwig 2016). However, we do not argue here that the reductive approach is preferable to alternatives. Our task here is to see what light can be shed on the nature of collective action, and in particular the case of EDI, by the basic reductive strategy.

At the same time, the project might be of interest to those attracted to nonreductive theories, or who hold that there can be group agents or plural subjects while denying that every collective intentional action requires such agents (see Pettit and Schweikard 2006 for discussion of such views). As the latter possibility indicates, one might accept the reductive account as an explanation for at least some collective actions, while also accepting the phenomenon of group agency. This is one of the reasons we are adopting the reductive approach here; in so doing we focus on elements that the reductive view and at least some non-reductive views might accept and build upon.

Yet another reason we adopt the reductive approach has to do with our particular interests in EDI, specifically issues related to the autonomy of individuals in this co-creative group process: what is it about the individuals in the group, and the relations between them, that contribute to its counting as a collective action? The reductive views focus on precisely this, and the framework they provide helps make perspicuous how the joint activity is built up from individual contributions, and therefore help us examine related questions about individual autonomy and distribution of agency in the practice of EDI.

Let ' $\mathrm{J}$ ' be a joint activity, such as moving a piano, rowing a boat, robbing a bank, writing this article etc. We propose to take the following conditions as individually necessary and jointly sufficient for collective (intentional) action that we J:

1. The we-intention condition: Each intends that we J.

2. The shared plan condition: Each intends that we J in accordance with a shared plan at the time of action (the time of J-ing). ${ }^{10}$

3. The intention-action connection condition: We J, and we do so because of successfully carrying out or acting on the intention that we J.

These conditions are essentially Ludwig's (see Ludwig 2016, p. 206). The first two are conditions for collective intentionality. Just as an individual's intention can fail to manifest in action, a group's shared intention can sometimes fail to manifest in collective action, and the third condition is meant to fill the gap. Ludwig's (2016)

102 entails 1, but it's useful to separate them. 
and Bratman's (2014) accounts are broadly compatible, and similar in many ways. Bratman attempts to provide conditions that are sufficient, but not all of which are strictly necessary for collective action. Ludwig worries that not all of Bratman's conditions capture something distinctive or characteristic of collective intentional activity. Ludwig intends the above conditions to be necessary and sufficient for collective action, though they are very similar to a core part of Bratman's set of sufficient conditions (see Bratman 2014, p. 152). Bratman's account includes the we-intention condition, and a number of conditions that are similar to the shared plan condition, but that are stronger or more demanding. ${ }^{11}$ Importantly, these include a condition to the effect that the members are mutually responsive to others' relevant intentions and actions in ways that successfully track the shared goal and guide the joint activity (this latter condition is meant to fill the gap between intention and action, and so plays a similar role as condition 3). We'll see that in the context of EDI the core conditions (essentially Ludwig's) are typically facilitated by the satisfaction of something like the condition of mutual responsiveness in Bratman's account. The condition is not strictly necessary for collective action but is typically the way in which we satisfy one or more of the core conditions.

Two important points regarding the we-intention condition before moving on: First, it should be possible to understand the joint activity "J" independently of the idea of shared or collective intentionality; no essential reference to a shared intention or collective intentional action in the content of the intention is required. (Otherwise, the account would be circular.) Second, what each of us intends here is that we J, and so we follow Bratman in rejecting what is often called the own-action condition, the claim that the subject having the intention to act must be identical to the intended agent of the action: "We seem... to be at home with a parent's intention that his son clean up his room, or a teacher's intention that the class discussion have a certain character, or a composer's intention that the performance of a finale be grand [...]" (Bratman 2014, p. 60). We will clarify other parts of the account in the sections that follow.

\section{I Intend that We Make a Dance}

What is the "J", the main joint activity that is intended in the case of EDI? It is the practice, performance, or creation of a spontaneous work with an improvisation

11 These include conditions to the effect that each intends to mesh their sub-plans, that the persistence of each person's relevant intentions depends on the persistence of others' intentions, and that the members know that these conditions are satisfied. 
ensemble. We might express the intention by saying, "I intend that we make a dance," referring to a single practice session or performance. But there is typically more involved, at least implicitly, in the intention. The aim is not merely to improvise nor to make just anything. An ensemble intends to be "tight," to borrow a phrase from jazz and other musicians. Serious practitioners intend to improvise together to make a dance that is good or of high quality in certain respects-for example, a work with a "choreographic" result, coherent organization, and intriguing aesthetic qualities. The joint activity can thus be quite complex, involving a cluster of goals, many of which are shared and some of which are a matter of degree (making a dance, making a good dance, making a dance that is good in specific ways, etc.). We may have succeeded in making a dance, and even succeeded in make one with such-and-such attributes, yet failed to make one with such-and-such other attributes.

Having this we-intention does not require that our underlying reasons and motives be shared. For example, I might intend that we move the piano because I want it in my house, and you might so intend because you'll get paid to do it. Similarly, underlying motives for joining an ensemble need not be shared. Members' different training histories, aesthetic values, and idiosyncratic goals inform reasons for joining, yet the shared intent to make an improvised work is likely supported by at least some shared experience and preparation in the field of dance. Often, dancers join certain groups over others based, in part, on the degree of shared values at the outset. Indeed, whether the dancers are let into a group can depend on whether they have matching values or intentions. "[O]ur shared agency," Bratman says, "frequently draws on subtle and frequently unarticulated commonalities of sensibility" (Bratman 2014, pp. 34-35), and this is certainly true in our artistic context. The degree of an ensemble's underlying commonality can determine whether the group has more or less of a head start in reaching the intended goals of the joint activity.

Now that we have described the "J" in this particular joint activity, how do we understand the "we" in this case? Sometimes the members of a group are determined directly, as when I intend that "we" move the piano, and "we" refers to individuals picked out by direct perception or by name. But this direct knowledge of each individual is not always at work and is not required. In many cases, the membership is determined indirectly, by some description like "the people at this party." In the case of EDI, I do not need to know which individual is behind me, or what that person is doing, to hold a we-intention. This is even clearer in cases where the number of people in a collective action is far too large for its individual members to be known, let alone directly perceived and tracked-for example, a flash mob, city parade, or protest march . In neither case is membership in the intended "we" contingent on direct knowledge of each and every individual. We 
are not saying here that believing oneself to be a member of a group is sufficient to be one - perhaps some recognition condition, to the effect that some sort of acknowledgement, now or in the past, from relevant members of the group is needed, even if there is no demand to know them all or know their particular intentions. $^{12}$

A related point: Dancers may come and go during the performance, (be "on" or "off") and this need not end the joint activity, nor does it change the "we" in the joint endeavor. It may seem an odd concept at first, but consider that, as a solo emerges and the performance is centered on a single dancer, each ensemble member must recognize the solo as such, and with each other member, refrain from entering the space. We might capture this by the contrast between "I intend that we dance" and "I intend that we make a dance." Different individuals might be directly involved at different times, and others' actions may consist of waiting, witnessing and tracking how the work is unfolding. In many cases, including paradigm cases of collective action, individuals can play different roles yet maintain the necessary intention that we J.

These points demonstrate how, despite changes in the perspectives or roles of individuals in the ensemble, the content of the primary "we-intention" (that we make a dance) can remain consistent throughout, both for any individual over time, and across different members.

\section{Parts and Wholes}

At the end of the previous section, we distinguished between the primary intention shared by the whole ensemble, an intention that we make a dance, and other specific intentions possibly only shared by some sub-group in the ensemble. These might include the intention that we dance at the same time, that we stand aside to make space for a soloist, that we roll the piano into a spotlight, that we mirror or counter each other's gestures, that we engage in wordplay, that we line-up or disperse, and so on. If members of the sub-group have the same we-intention to do $\mathrm{X}$, and they succeed in performing $\mathrm{X}$ by carrying out the shared intention, then such sub-group activities count as collective activities.

What is the relation between the collective activity of making a dance and these "smaller" collective actions or activities? Well, these are constituent parts of the activity of making a dance, ${ }^{13}$ just as our moving the piano out of the truck, through

12 We are grateful to a referee of the journal for helping us see the need to be clear here.

13 These constituent parts need not be pre-determined, and their role in the activity might be understood only when viewed in relation to the whole. 
the front door, and up the flight of stairs are parts of the collective intentional activity of moving the piano up to the second floor. Sub-groups of individuals may take turns or play different roles at different times - getting the piano onto the dolly, turning one end while the other is held still, taking the door off to expand the opening. Many collective achievements are thus constituted, at least in part, by "smaller" collective achievements of the whole group or some part of the group. This is not to say that this is always the case or must be the case. Collective actions are often constituted primarily of individual actions. Factory workers on an assembly line might each perform an individual action that does not involve any others, and all these individual actions might together constitute the making of the product. If the workers share the intention to make the product and the product is made because of this intention, then it can count as a collective action.

A collective performance can similarly be constituted, in large part, by various individual actions. A three-member dance might, for example, be constituted by three solos consisting of individual motions; each soloist, in turn, takes (or is given) the spotlight as the other two members abstain from joining; or three members decide to perform simultaneous solos, perhaps thinking it interesting to put individual choices side-by-side. A more typical performance draws on a spectrum of constituent parts, from individual to sub-group to whole group actions. Individual actions are of course always needed-they form the basis of any collective choreographic event, improvised or otherwise. However, with no pre-planned choreography, it would be difficult for an ensemble to attain or even approach its aesthetic ideals for the performance without building on collective intentions and actions of sub-groups. Moreover, even if some movements are accidental or at some level unintended, they provide fodder for subsequent actions of the group or its members. We'll return to these ideas in our discussions of spontaneity (Section 5) and training for coordination (Section 6).

\section{Sharing and Intending under Uncertainty}

Our account requires that individuals act in accordance with a shared plan at the time of action. Note that we are not requiring that all details and sub-plans be shared or agreed upon. Two people can succeed in playing chess together, as a collective intentional act, even though part of their intention is to frustrate certain sub-plans of the other. In so doing, they agree to play chess in accordance with a shared plan, without agreeing on all sub-plans. In other cases, one person might deceive another with respect to certain sub-plans towards a common goal, but only 
enough to outshine or outdo the other, not enough to get in the way of the collective activity (Ludwig 2016, p. 253). ${ }^{14}$

Moreover, the account doesn't strictly require that the plan be shared in the sense that each person knows that others have similar intentions and plans. It doesn't even require that each person believes that others have similar intentions and plans. What is required is that they have the same plan in mind at the time of action, whether they know or believe that they all do or not. This might seem like a mistake. Should there not be some communication, confirmation, or ongoing interaction, in order that their plans mesh? Should they not satisfy what Bratman calls the mutual responsiveness condition (Bratman 2014, p. 79): "Each is responsive, in her relevant intentions and actions, to the relevant intentions and actions of the other, in a way that keeps track of, and guides in the direction of, her intended end of their joint action [...]"?

Not necessarily. First, consider the idea of responsiveness. As Bratman explains, being mutually responsive to the relevant intentions and actions of others plays an important role in many ordinary cases of collective action, yet he recognizes that it is not required in all cases. Consider the case of synchronized divers, in which the meshing of sub-plans is "pre-packaged"; once the divers leave the board, they have little to no opportunity to respond to each other, but must carry out the prescribed plan as best they can (Bratman 2014, p. 81). Mutual responsiveness is thus not strictly necessary for collective action.

Second: It also doesn't seem, on reflection, that knowledge, belief, or even a high degree of confidence that the relevant intentions and plans are shared is required. We have no difficulty thinking of cases of individuals intending to do things despite very low confidence in success (intending to reach the summit of Everest, or to convince an uncle to switch political parties), so why not think the same when it comes to joint actions? (Perhaps some degree of confidence, or some hope, of achieving the end is required.) Ludwig provides an illustrative example: a country has just been the target of a pre-emptive nuclear strike, and three missile operators at separate locations are responsible for operating silo 451. Though their communication channels are cut, and no one knows if any of the rest of the team is still alive:

Each punches in his code, and then turns his key, hoping that there are still others who are doing their parts, however unlikely it may seem; and so they launch the missile in silo 451 together, according to their prearranged plan, and they do so intentionally (Ludwig 2016, p. 221).

14 To see how a shared plan can accommodate some variation or "margin of error," see Ludwig (2016, p. 214). 
Notice that not only is this another case (like the synchronized divers) in which the collective action does not require mutual responsiveness, but the subjects fail to have much confidence, let alone know, that others are acting on the relevant plan. Denying that these conditions are necessary allows us to accommodate cases of collective action involving uncertainty and little or no explicit verbal communication, which is relevant to EDI. While there is communication in an ensemble, it is not the kind that definitively exposes and sorts out individual intentions in the same way that a conversation or a pre-arranged plan might.

One possible objection at this point is that while something like mutual responsiveness and knowledge of shared plans is not required throughout, it is arguably required at some point or other. It may be useful here to distinguish between the planning stage and the execution stage of the activity (which may overlap). While knowledge and mutual responsiveness might not be required at the execution stage, that leaves open that it is still required at some stage or other. For example, in the actual diving of the divers, mutual responsiveness is not required; and in the turning of keys on the part of the missile operators, neither mutual responsiveness nor knowledge that others share the plan is required. But according to the objection, such knowledge of and mutual responsiveness to others' relevant intentions and actions must be satisfied at the planning stage at least, if not at the execution stage. ${ }^{15}$

Our reply is that, while the above examples from Bratman and Ludwig may be problematic in the way that the objection suggests, when we consider other examples we find it intuitive that the actions are collective despite failing to satisfy either a knowledge or mutual responsiveness condition. To take a simple example, based on similar cases that Ludwig gives in response to objections of just this sort: ${ }^{16}$ think of a case in which two people who know each other well each dream that the other has proposed doing something together, completely coincidentally, and as a result they each form the intention to do it with the other. Maybe the activity involves their interacting, and maybe not. But they do both execute their intentions and do their parts. Didn't they do it together intentionally? How they got in the state of having the shared intention to do something is one thing. Being in the state is another. Following Ludwig, we hold that the latter is what is required. Note that this is still very different from the case of two hikers who happen to be hiking on the same trail, for the hikers might share the intention to hike, but they

15 We are grateful to a referee for raising this concern.

16 The objection (and Ludwig's response) was given by Michael Schmitz at a symposium on Ludwig's book at ENSO V: The Fifth Conference of the European Network on Social Ontology, Lund Sweden, Aug. 30-Sep. 1, 2017. We are grateful to Kirk Ludwig for his correspondence with us on this point. 
might not share an intention directed at the joint activity: neither intends that they hike together. ${ }^{17}$

Though these conditions are not strictly necessary for collective action, satisfying them often helps the participants to collectively intend and carry out the joint activity. For example, it is often by knowing or at least believing that others have the relevant intentions that we are moved to adopt the intention as well. And mutual responsiveness to the relevant intentions and actions of participants often explains how we manage to mesh sub-plans well enough to succeed in carrying out the intended activity (thereby satisfying condition 3 of the core account). As we examine the case of EDI further, we'll see that, given the lack knowledge of specific sub-plans and intentions of others, mutual responsiveness becomes a core skill for the expert improviser and plays a pivotal role in this type of joint activity.

\section{Plans, Spontaneity, and Indeterminacy}

For some improvisers, the word 'plan' may initially cause negative reactions bordering on anaphylaxis. After all, improvisation essentially involves a high degree of spontaneity. However, what is meant by 'plan' in theories of collective action can differ from how the term is often understood to imply pre-arranged steps or prescribed roles. After clarifying Bratman's and Ludwig's uses of the term, we will ask: what does a shared plan look like in the dance improvisation context, and how and when does it typically come to be adopted or shared?

The focus in the literature on examples that lack spontaneity can give an impression that cases like EDI cannot be accommodated, or that they would shed little light on the theory. This impression can be reinforced by Bratman's calling his theory a "planning theory of acting together." Although Bratman's theory takes planning capacities as central to the exercise of individual and collective agency, "these planning capacities are embedded in a complex psychic economy that also involves abilities to characterize one's plans in [...] open ways, and to be spontaneous and flexible as time goes by" (Bratman 2014, p. 24). Bratman takes such traits as openness, spontaneity, and flexibility, to be "practical virtues that are involved in well-functioning planning agency" (p. 24). Bratman is explicit that one's plans are typically and sometimes grossly incomplete and need not involve

17 That said, if some of our readers have a conflicting intuition, or want to insist that some knowledge condition or mutual responsiveness condition (or both) is required, they are free to add it to the core account we have offered. But they should not insist that knowledge that others share the intention is required at the execution stage. 
having specific steps or means to the goal in mind beforehand (see Bratman 2014, pp. 23-4).

Ludwig's account also allows for spontaneity. When we think of plans, we usually think of a kind of recipe for action, "a series of actions carried out in a particular order with the goal of thereby bringing about an event or state of affairs" (Ludwig 2016, p. 213); and when it comes to a plan for collective action, we usually think of an assignment of roles for carrying out parts of the plan. However, Ludwig allows that, in the limiting case, a plan could just consist of one step. Moreover, even for complex activities, participants in a collective can share a plan but leave open the exact steps. As we have already mentioned, what Ludwig requires is that the members act "in accordance with a common plan at the time of action" (Ludwig 2016, p. 206). He thus allows that in many cases a specific shared plan is deferred to the moment of acting, while in other cases there is a "pre-arranged shared plan" (Ludwig 2016, p. 221).

Thus, far from being at odds with the "planning theory," EDI fits comfortably and can be accommodated by this approach, which is interesting and significant given that the high degree of spontaneity makes it a marginal or atypical case. ${ }^{18}$ It is the sense of plan as involving multiple, pre-arranged steps that we employ in our title, "unplanned coordination." In this ordinary and common sense of the term, EDI is "unplanned" in that there are few, if any, prearranged steps or prescribed specific roles (beyond being improvisers) to the activity. Most plans are made on the spot ("at the time of action"), through a group process, and without explicit verbal consultation, and in that sense, they are unplanned or unscripted. Yes, we plan to gather at a certain time to improvise, but we don't have a plan as to what moves we will make when we do so. To the contrary: we do not plan what we will do until we're doing it; we know that we will gather to make an improvised dance, yet we do not know the content and form of the dance in advance. In this sense, we could better capture the we-intention thus: I intend that we make a dance, without our knowing in advance what steps we will perform.

In lieu of prescribed steps, how do members in a dance ensemble contend with this level of uncertainty in the collective activity? A relevant training prompt is that "you do not need to know what you are going to do, but you do need to know what you are doing."19 That you know in the moment what you are doing may seem obvious, but in fact, it takes practice to stay awake to your own actions, and not attend exclusively to others, or have your mind on unrelated matters (e.g., replaying irrelevant scenes from memory or thinking about where you should

18 Just to be clear, though we claim that EDI is atypical, we are not saying it is categorically different from other forms of collective action; the difference is one of scale.

19 Jennifer Kayle, co-founder of The Architects, a 5-member dance improvisation ensemble. 
go for lunch). Amidst the internal complexities of group creation, intention arises out of perceiving what's happening, and for improvisers, the convergence of perceiving, intending, and acting can be instantaneous. With training, appropriate intentions can be formed-and-carried-out, rather than formed and deferred to a later time of execution. Thus, an ensemble can share a specific plan, in Ludwig's words, "at the time of action."

There are other ways that improvisation accommodates some planning, whether individual or collective, that is cross-temporal since, over the course of a longer performance, intentions can be recurring, remembered, or ongoingly adjusted in the process of tracking an overall sequence. As a work unfolds, an individual, sub-group, or whole ensemble can call back a previous theme, for example, to harmonize the ending with what happened in the beginning. Though future-directed intentions may form in response to emerging scenarios, performers are also ready to abandon those intentions just as quickly as their points of view shift and scenarios arise and change. One of the challenges for an improviser is to be spontaneously and creatively responsive to what is going on in that instant, while also tracking and supporting the coherence of the overall work.

\section{Training for Coordination}

In EDI, there are training techniques to develop and strengthen the ability of participants to be mutually responsive. Let's consider strategies articulated by The Architects 2010 (founded 2002), one of the most long-standing improvisation ensembles still practicing today. ${ }^{20}$ Though several other professional ensembles have also invented and practiced techniques that may be called "ensemblebuilding," The Architects' pedagogy, developed over two decades, ${ }^{21}$ is broadly representative of other improvisation ensembles and their practices, and is relevant to our questions concerning the relation of each individual's actions to one another and to the group. ${ }^{22}$ Their instructional practices instill an expanded attention and related skills, enabling dancers to act on individual impulses and

20 The Architects practice ensemble improvisation in performance and they share administration of their company business, operating and organizing as a "collective." The latter is atypical in the dance field at large, and though more typical among improvisation groups, still less common.

21 For more on the Architects and their instructional practices, see https://www.architectsdance. org/about.

22 Other contemporary professional practitioners and ensembles whose pedagogy addresses building both individual and ensemble capacities include: Susan Sgorbati's "Emergent Improvisation” ensembles (Vermont 2000-2013), Lower Left Collective (San Diego, 1997-2006, expanded 2007-2020), The Lovelies (New York 2013-2020), The Giants of Sciants: Penny Campbell, Terry 
toward group outcomes simultaneously. To that end, dancers train to achieve individual virtuosity and expertise, but they do so in a group context. Each member is challenged to be aware simultaneously of her own impulse and intent, what others are doing, and what is happening in the ensemble overall. The individual's capacity to make (often sudden) choreographic choices at the convergence of self, other, and group, is a skill that steers and unifies the unfolding performance. This kind of multi-awareness is the brass tacks of EDI.

Major aspects of training for this type of artistic practice are concerned with the ability to improve perception and attention. ${ }^{23}$ Good dance improvisation pedagogies teach complex modes of "listening" to both inner and outer sources of information. Inner listening strategies improve attention to sensation and use sensory stimuli to direct movement exploration. Dancers immerse themselves in kinesthesia, but also imagination, feeling, thought, and memory. An important awareness to build is the awareness of one's own perceptual process. This metaawareness may be prompted by the directive "notice what you notice." ${ }^{24}$ While inner listening is considered fundamental fuel for individual intent and action, intent is also sparked by profuse external stimuli (visual, auditory, and tactile) making it a challenge to absorb and relate in organized ways. Tuning one's listening in both directions, inner and outer, is a core skill in ensemble participation.

Consider a training strategy that instructs each dancer in a duet to develop her own choreography (as in dancing a solo) while simultaneously noticing her partner's actions. ${ }^{25}$ To look over at a partner and not automatically begin following and joining what she does is a skill that is surprisingly difficult, especially for dancers whose early training involves learning by imitation. To spontaneously join and match what others are doing also requires training. Once an improviser can do either, adopt a partner's movement or develop her own, this dual capacity then affords and expands choreographic choices, for example, to mirror and incorporate, or contrast and counter what others are doing.

Such training improves group coordination and coherence in the work; at the same time, it cultivates the robust agency of individuals by developing their capacities to make their own choices in a constantly evolving event. This turns out to be a crucial balancing act since the freedom and power to act upon the unfolding work is distributed among members. Given the distributed agency to affect the

Creach, Peter Schmitz, Susan Sgorbati (Vermont 1983-2005), and Katie Duck's "Magpie" (Amsterdam 1995-2005).

23 See the discussion of Penny Campbell on "ensemble awareness" in Buckwalter (2010, pp. 16-17).

24 Katherine Ferrier, co-founder of The Architects.

25 Peter Schmitz, at WIPI: Work in the Performance of Improvisation. 
work, a dance is likely to be disorganized if members of the ensemble are heavily biased toward inner attention, and fail to join, relate, or intersect with others. On the other hand, a dance is likely to be simplistic or repetitive if individuals are consistently biased toward outer attention, disconnected from their own creative thinking, and primarily focused on following others. Of course, it's also possible that dancers who are attentive, both inwardly and outwardly, fail or refuse to engage in constructive ways with what they perceive; this would be a failure of mutual responsiveness that affects the outcome. Though this is not necessarily required to meet minimal conditions for collective action in the case of EDI, and even to achieve its demanding aesthetic goals, an ensemble is more likely to achieve their goals if its members respect and take seriously the contributions of others, while remaining committed to their own artistry and creativity. Rigorous ensemble training finds ways to balance and integrate these: tending to the needs of the emerging composition, respecting others' contribution and agency (and responding accordingly), and building/contributing one's own creativity and virtuosity.

This balancing act casts an interesting light on what counts here as cooperation (more on this in Sections 7 and 8). Practitioners learn early on that cooperation in EDI is not identical to agreement. ${ }^{26}$ The unplanned coordination that co-creates the work doesn't foreclose anyone's ability to counter, abstain, protest, or diverge in some way. It is sometimes a tacit and sometimes an explicit value in the ensemble ethos that disagreement about where the work is going, or should go, and the counteractions that arise, are central to the creativity and innovation of the ensemble. Though participating in a collective act, dancers are developing virtuosity as individual decision-makers. In the following sections, we will consider what significance these skills and capacities may have beyond being means to good improvisational composition.

\section{Cooperative and Non-hierarchical Collective Action}

Bratman distinguishes between a collective action in general and what we might call cooperative action. An action can be collective and yet uncooperative, in the sense that someone is forced or coerced, or somehow tricked or deceived, into engaging in the activity. For example, two parents might be coerced into helping someone carry out a crime, such as robbing a bank, under the (possibly false)

26 They agree, of course, at the level of intending to make a dance. 
threat that their kidnapped children would be harmed. In such a case, the conditions for collective action might be satisfied. The parents might decide to commit to the task and work together to perform it under immense pressure. (In other cases, the sort of deception or coercion at play might interfere too much with the activity and lead to failures of collective action.) They might even collaborate effectively with the kidnapper in pulling off the heist. As this possibility highlights, being coerced into adopting a goal is compatible with a sharing of agency with respect to how to achieve that goal.

Conversely, a collective action might fail to be cooperative-fail to incorporate a robust sharing of agency-with respect to how to achieve the goal, even if it is cooperative in the sense of not coercing or deceiving one into adopting it. Even when collective activities are uncoerced, they may involve extensive plans that are outsourced or imposed on the group by some means (e.g., factory workers following prescribed action sequences, or musicians playing in an orchestra from notes on a score). In some of these cases, individuals might freely decide whether to take part, but have significantly reduced latitude in how to participate in the joint activity.

A collective action might fail to be cooperative in either sense (in relation to participating or adopting the goal at all, or in relation to the specific way the activity is carried out or the goal achieved).

Turning to the context of dance, a traditional dance company typically functions through assigned roles such as director, choreographer, and performer, and affords the planning and decision-making to some while withholding it from others, even and especially in the creative workings of the company. This is a traditional model for repertory companies whose plans are established by choreographers and carried out by dancers who often have far less latitude in fulfilling the assigned roles. This way of producing and performing a dance can meet conditions for collective action, but there is a direct and inverse relationship between the specificity of the prearranged plans (that are carried out via hierarchical roles) and the extent of freedom that participants (disproportionately) have with respect to how to carry out the joint activity.

By contrast to the above examples, EDI typically involves a robust freedom and sharing of agency in both senses described above (i.e., with respect to the goal, and the means of achieving it). Focusing on the means, each member is responsible for the process and choreographic quality of the work. The primary activity-making a dance-is not outsourced or imposed, but is formed via an internal, ongoing negotiation that individuals may affect directly. Roles are not assigned or fixed; they are fluid-at any given moment, different individuals may, for example, lead, follow, join, observe, or diverge, and may switch roles as the work unfolds. 
Though cooperation and sharing of agency is not strictly necessary for collective action, in the case of EDI the adoption of cooperative and egalitarian ideals in the workings of the ensemble is likely to promote, and may even be practically indispensable for, achieving the aesthetic goals of the joint activity. ${ }^{27}$ Other things being equal, EDI is less likely to achieve even the classical or formal aesthetic goals (which we will discuss in Section 9) without there being some substantial degree of cooperation and sharing of agency or responsibility in the group. In a context where members know so little of what they and others in the group will do, and where individuals are free with respect to how to contribute to the joint activity, it will be difficult for the group to attain the shared classical or formal aesthetic goals to a significant degree without being attentive to the contributions of others, collaborating with them, while also making constructive contributions of their own. We therefore claim that a good case of EDI will at least typically be a joint, cooperative achievement of free individuals exercising their autonomy in skillful ways.

Given the role of cooperation in the ensemble's meeting its artistic goals, it's important to recognize that effective cooperation is not automatic; ensembles edge closer to realizing cooperation and a robust sharing of responsibility over the work when these ideals are actively sought, are out in the open, and overtly influence artistic practices of the group. When egalitarian ideals are undercut (by "dance hogs" who take up too much space, or by someone who ignores others in the creative process), the freedom that each individual has to directly counter these events gives opportunity to at least frustrate those who would try to hoard power in the dance-making process, and to maintain and work toward shared artistic goals. ${ }^{28}$ Fischlin et al. describe this tension thus:

Despite claims about improvisation's liberatory potential, there are ample instances of improvisational musical practices that don't work in the model ways that we're suggesting they ought to. Furthermore, these instances need to be confronted squarely and honestly. [For example] where they've relied on habitualized gestures, where musicians have been unable or unwilling to listen to one another, where they've deployed authoritarian musical gestures, where they've been more focused on the development of their own virtuoso techniques than with the collective endeavor. But even in the so-called failed improvisations there always remains the spark of what might have been: the fact that chances were taken (or not) and that the performative agency enacted, however successfully, can still teach the listener something valuable (Fischlin, Ajay, and George 2013, p. 205).

27 Note that in saying these ideals are adopted or valued, we are not saying that they need be valued for their own sake - recall that ensemble members do not need to share all underlying motivations.

28 See Fischlin, Ajay, and George (2013) for broad discussion on the tension between "liberatory" ideals and the obstacles to their achievement in jazz "musicking” (Chapters $2 \& 3$ ) and for discussion of failure to respect and serve the relationships that are at the center of the music (Chapter 6). 
Part of the value of EDI is that it at least typically aims to be a highly coordinated and highly cooperative, non-hierarchical collective practice. Whether or not these aims are perfectly met, this case productively complicates any crude formulation that pits the efficacy of the complex collective act against the freedom and power of the individuals who participate in it. But to fully appreciate this point, it helps to reflect on individual autonomy and how it might be exercised in the improvisational context.

\section{Autonomy and Freedom in the Group}

In the previous section, we noted that collective activities need not be cooperative or free from coercion and deception; and they need not involve a significant degree of freedom with respect to how individuals contribute to the joint activity. EDI enjoys both to a high degree-not because there are no specific goals and anything goes, but because there is no specific plan as to how to achieve the goals, and creative, spontaneous input from the members is by definition part of the practice. But it is important not to confuse either of thesefreedom from coercion, deception, or external constraint, and freedom over how to achieve the goal-with autonomy, the capacity to govern one's own actions. Freedom from external constraint might be necessary for autonomous choice, but it is not sufficient; a young child, or an adult with a severe addiction, may be free (unconstrained) but fail to act autonomously. Freedom in how to achieve a goal is neither necessary nor sufficient for autonomy. It is not necessary, since one might act autonomously in pursuing a goal in full realization that there's only one way to achieve it. And it is not sufficient, since the fact that many options are, in principle, open to one does not show that an option was taken up autonomously. Even in the absence of external forces that narrow or restrict the options available, certain internal, psychological forces (e.g., addiction) can undermine or diminish one's capacity to govern one's own actions.

As Buss and Westlund (2018) make clear, one of the central challenges for accounts of autonomy is to distinguish the autonomy-disrupting internal factors from those that are involved in the self-governing process. Following Westlund, we find it useful to think of autonomy as requiring a "dialogical disposition to hold oneself answerable to external, critical perspectives on one's action-guiding commitments" (Westlund 2009, p. 26). This provides at least an initial answer to the question of what sort of ability is involved in one's capacity to govern one's own 
actions. On this view, in order to "count as governing one's practical reasoning, rather than being in the grip of considerations that drive it, one must be open to engagement with the critical perspectives of others" (p. 35). This is "a feature of the agent's psychology, and thus internal to the agent" but "nonetheless a disposition to be engaged by what is external to the agent, that is, by points of view other than her own” (p. 22). Autonomy is, in a way, irreducibly social or relational, for it requires "an irreducibly dialogical form of reflectiveness and responsiveness to others" (p. 28). However, it is modestly relational in that, unlike some other accounts (e.g., Oshana 2003), it doesn't require that anything approaching an ideal social context be in place, or that one stand in egalitarian relations to others. This is important, since it allows us to say that at least in some cases, a person in non-ideal circumstances can autonomously engage with others and even autonomously endorse a non-ideal situation. ${ }^{29}$

A simple example from Westlund will help us better appreciate her account before we apply it to EDI. Consider an Afghan woman who willingly embraces the rules imposed by the Taliban. On some views, like that of Oshana (2003), she should not be considered autonomous no matter what her attitude toward the strictures imposed upon her. While Westlund agrees that relations of subordination can often undermine one's autonomy, she rightly takes issue with Oshana's stronger claim.

A "Taliban woman" who is prepared to take up and respond to perspectives of others, even if she is unconvinced by their arguments, is strikingly different from one who is not. We may find the content of her commitments to be utterly wrong-headed, maybe even in part suspect they will erode her own autonomy competency over time and irreparably stunt the development of such competency in her daughters. But to treat her as non-autonomous [...] [or as one who] lacks authority over her own voice [...] flies in the face of the evidence she gives of such authority in engaging in just the kind of critical dialogue in which one might expect reflective, self-governing agents to engage (Westlund 2009, p. 29).

Note that for one's choice or action to be autonomous, it is not required that it be a good one (that it be reasonable, optimific, morally permissible, etc.). One might make a bad choice while still being disposed to engage other perspectives, to consider them seriously. But the disposition must be genuine; that one seems to oneself to be autonomous, disposed to engage with others' perspectives, is not enough, since that might itself be an illusion; and that one has a basic ability to

29 The account is neutral with respect to the compatibilist and incompatibilist debate, as it only provides a necessary condition for autonomy. That is, one might accept Westlund's account and claim that being autonomous is compatible with determinism; or one might add to the account some condition to the effect that the choice must be caused by the agent and not determined by preceding events. 
engage with others' perspectives is not enough either, since having the ability is compatible with not ever being disposed to use it. Note, moreover, that one's autonomy might vary from context to context: I might be disposed to engage other perspectives on political matters but not on religious ones. Or I might be disposed to consider others' views on the state of my finances, but not on the state of my marriage.

Let us return to the context of EDI. Before focusing on autonomy in this context, let's briefly discuss freedom and opportunity for action. Consider an ensemble member who begins a dance by choosing to stand somewhere in the studio space. This presents a certain constraint in that I am unable to initiate the beginning (because someone else played that role) and should I desire to occupy that very space, I am unable to do so. But I am now free (and inspired?) to act in numerous other ways; I can take any number of actions that place me in relation to this individual. This relation could have spatial, contextual, dramatic, or other qualities. The fact of being an autonomous agent has not essentially changed; the freedom to act, though minimally constrained as described, is in other ways prompted, given an expanded context and opportunity to be exercised.

We often expand the reach of our agency through the presence of others. We can collectively produce compositional and aesthetic forms that no one of us is able to create alone, for example, impressive lifts, catapults, or other physical feats. Some compositional forms require group activity, such as call and response, foreground/background arrangements, or temporal structures like canon. When a group of people perform the same action at the same time, this is called unison, a form that can change the significance of an action simply by performing it as a collective. That the presence of others might expand one's options illustrates how freedom and cooperation are deeply intertwined in EDI.

What does it mean to say that an ensemble member's choices and actions are autonomous? In keeping with Westlund's model, it would mean that one is disposed to engage with the perspectives of others in making one's own choice. The relevant perspectives considered might be hypothetical ones (different courses of action in the improviser's own imagination), but they certainly include actual others in the ensemble. In this context, these perspectives have a shared or overlapping starting point. The intention is to make a dance together, one that aspires to certain aesthetic ideals, but also (at least typically) certain cooperative and egalitarian ideals: everyone is to be treated as an equal, with no fixed hierarchical structure, coercion, or manipulation; no one's suggestive movements should be prioritized or ignored merely because of who they are; everyone is expected to contribute and take responsibility for the creation of the work. The intentional movements, gestures, and interactions of the improvisers are understood by all to be part of the dance, and as material that may suggest other movements and 
interactions. These shared assumptions and intentions help determine how to interpret the actions of others in the space, making a certain kind of dialogue possible. To be autonomous with respect to these choices requires that one be disposed to engage with the perspectives of other improvisers (perspectives that are suggested by their actions in the space) in making one's own choice of action. In this context, far from autonomy and cooperation being opposed to each other, genuinely autonomous action on the part of those who share these assumptions or starting points tends toward cooperation, since it involves a disposition to engage with perspectives other than one's own. When we consider the more extreme case of coercion, the connection of autonomy and improvisation is even stronger: if specific actions are coerced, then they are not improvised, and a fortiori cannot be collectively improvised.

It is worth noting that recent literature on the aesthetics of improvisation explicitly invokes the idea of a dialogical process in a way that makes Westlund's account strikingly apt, and connects it with the idea of mutual responsiveness.

[G]roup improvisation involves essentially dialogical engagements between the improvisers, so that they are compelled to communicate with one another, all parties receiving, negotiating, responding to, and attempting to create meaningful (musical or performance) utterances and gestures in real time. The precise way this dialogue unfolds has often been portrayed as the primary locus of the aesthetic distinctiveness of improvisation (Born et al. 2017, p. 10).

It is important to keep in mind that an autonomous choice is not necessarily a good choice. One might be strongly disposed to consider the relevant perspectives of others, but for some reason fail to do so. In EDI, one may fail for lack of training, an inflated ego, or attention fatigue. Even if the ensemble avoids the more ugly and obvious ways to disrespect or devalue another's autonomy (e.g., coercion or deception), subtle failures could remain (e.g., manipulation). Besides being morally problematic, these failures could undermine the activity's aesthetic success. We might build this into the we-intention schematically thus: I intend that we make a dance that meets such-and-such aesthetic, cooperative and egalitarian ideals. Recall, as discussed in Section 2, that the joint activity can be complex, involving a cluster of goals, at least some of which are a matter of degree. We may succeed in making a dance that satisfies certain goals, while failing to make a dance that satisfied others. Moreover, the underlying motivations can vary; some might intend the cooperative and egalitarian ideals merely for sake of aesthetic or other goals, while others might intend them at least partly for their own sake.

As we shall see in more detail in the next section, there is a sense in which the egalitarian and cooperative features typically conducive to a successful 
performance of EDI are not just means to aesthetic value; nor are they merely extrinsic, pragmatic or moral ideals. They are, rather, partly constitutive of the aesthetic value, whether the members of the ensemble value it for its own sake or not. For what is on display in a good case of EDI is a significant collective achievement, one that manifests an impressive, spontaneous, jointly cooperative and individually highly autonomous activity that meets demanding artistic standards. That can be a beautiful thing to behold, its beauty at least partly a function of our admiration and love for cooperative achievements of autonomous individuals in society more broadly.

As the complex relationship of autonomy, freedom, and collectivity in EDI comes into high relief, this should prompt sophisticated ensembles to ask investigative and pedagogical questions about their modes of training. For example, are all participants respected and valued? Are their abilities fostered and supported, their perspectives and contributions welcomed and taken seriously in the creative process? To what extent and in what ways do their practices and habits expand or limit the freedom of participants? What are the more specific social and aesthetic ideals that they share? How are aspects of the training aligned with the ensemble's social ethos and its preferred aesthetic?

\section{Value and Evaluation}

How does our discussion of collective action theory inform the aesthetic evaluation of EDI? If evaluated in ways traditional to (non-improvisational) choreography, for example by examining its formal composition, precision, or synchronization, many of its iterations would be judged inadequate and inferior to "set" choreography. On these formal levels, the spontaneously organized, thematized, and performed cannot easily compete with a choreography that is honed over long periods of reflecting and editing prior to being performed. But one of the beauties of EDI stems from the lack of knowledge of what is about to happen, and relatedly, the lack of opportunity for editing. All actions taken by the dancers are on display, good or bad, without erasure or revision, and without the benefit of selecting and refining elements of the work. The virtuosity on display is that of composing something choreographic-coherent and organized, innovative or surprisingwhile contending with significant uncertainty regarding what is about to be composed, and doing so without hierarchical, pre-assigned, fixed roles. To evaluate its form while ignoring the spontaneity of its production is to miss the point, or at least miss the central nature of its virtuosity. Likewise, to evaluate it without regard to the mutual responsiveness and cooperation on display is to ignore some of its core virtues. In seeing it as a cooperative action, we can begin to appreciate 
EDI not only as an artistic achievement, but also a social one; dancers freely work together in complex ways on a difficult task-wresting order and meaning out of what, at times, seems like thin air. In this context, we can see that it is no simple or easy task to satisfy the conditions for collective action; thus, the improvised nature of EDI is the central aspect of its virtuosity and aesthetic character, and also part of what makes it an impressive collective achievement.

EDI is an overtly social process, one where, at least typically, cooperative artmaking is achieved via a robust exercise of individuals' autonomy. The social process that creates the work is not separate from it, but in some sense is the work. How do we locate and analyze the aesthetic value of such a practice? Classical aesthetic frameworks analyze the formal or representational properties of the art object; whether the value is judged by degrees of unity, harmony or coherence, or by some sort of formal representation or communication, classical aesthetics primarily consider the art object apart from its creation, its makers, beholders, and their relations. In the introduction to their volume, Improvisation and Social Aesthetics, Born, Lewis, and Straw find these classical frameworks problematic for having "neglected the ways in which one's location and embeddedness in a particular culture and social milieu affect one's aesthetic judgments, the role that such social location might play in aesthetics, and questions of whether and how social experience might itself be immanent in aesthetic experience" (Born et al. 2017, p. 1).

As EDI performs its own making through a complex social process, a lens with a wide enough aperture is needed to recognize that its social process is embedded in the aesthetic experience of the work. Yet it is not uncommon to find the evaluation of dance improvisation carried out as one might evaluate western concert dance and choreography, primarily through the formal aesthetic ideas that have historically permeated much of the thinking in the field (see Marks 2003). Doris Humphrey, one of the so-called "four pioneers" of modern dance, ${ }^{30}$ wrote an influential text called The Art of Making Dances (Humphrey and Barbara 1959) in which she explained how to make good choreography by discussing formal topics such as "design," "dynamic," and "gesture," and proposed rules of thumb such as "symmetry lacks life," and famously, "all dances are too long” (p. 159). Another famous mid-century thinker who influenced dance analysis was Rudolph Laban, whose formal system LMA, Laban Movement Analysis, focused on four categories: body, effort (sub-elements: space, weight, time, flow), shape, and space. Building in part on Laban's work is The Intimate Act of Choreography (Blom and Chaplin 1982), an oft-used text in academic choreography classes. In it, practitioners are led

30 National Educational Television and Radio Center at Indiana University, Bloomington (1966). Dance: four pioneers. Released by Indiana University Audio-Visual Center. 
to explore time, space, and force as "choreographic elements," along with "devices” for making and manipulating movement so as to produce works that exhibit a sort of holy formal trinity: unity, variety, and contrast. Some traditional evaluative frameworks for choreography highlight or at least include dramatic or theatrical characteristics and the feelings they provoke, yet the social relations they take to be "in the work" are those merely represented in the drama portrayed. While evaluation in the field of dance has certainly evolved, formalist notions are remarkably hard to decenter and counter. ${ }^{31}$

Standing in contrast to the comparatively narrow focus of purely formalist aesthetics (on dance performance in general, and EDI in particular) is social aesthetics, a framework that would allow us to consider the real social relations between the improvisers as improvisers. Overall, the framework of social aesthetics employs at least two modes that acknowledge social phenomena in aesthetic analysis: one considers the "social conditions bearing on experiences of and judgments about art objects, including how these conditions inform the creation, dissemination, reception, and import of such judgments," and the other examines "performance processes and events themselves, showing not only how they are mediated by wider social conditions and institutions but also how they are immanently social and may in turn proffer-or better empractise-novel realms of social experience, new modes of sociality" (Born et al. 2017, p. 9). It's useful to clarify that social aesthetics is not unconcerned with traditional aesthetic notions of the beauty and proportion of the art object, but rather subsumes these in its broader analysis (Born et al. 2017, p. 4).

In her chapter, “After Relational Aesthetics,” Georgina Born further specifies the overall project of social aesthetics by articulating four distinct yet related "planes" of analysis, a plural approach that she advances in order to avoid reducing social aesthetics to a mere matter of social "context” (Born 2017, p. 39). Roughly, her four planes consider (1) what she calls "microsocialities," the social relations and interactions that, in some way, make up the substance of the artwork; (2) the way that art reflects (with the possibility of distortion) social realities and changes present in background social or artistic institutions, or in society more broadly; (3) ways that artworks may introduce or suggest new possibilities or their more serious adoption, whether in the arts or society more broadly; and (4) ways that art can be a form of activism seeking to make direct impacts in social or institutional realms.

Our discussion of EDI is related to the first three planes. Consider the first plane. As Born et al. explain, the practice of ensemble improvisation involves "dialogical engagements" where all parties are "receiving, negotiating, responding to" one another (note that this is essentially mutual responsiveness); and "the pivotal point"

31 For example, see Banes (1994) for an evaluative framework that includes contextual analysis. 
is that "the dialogical aesthetic practice is also, immanently, a social interaction" (Born et al. 2017, p. 10). By taking seriously that the cooperative activities are the "microsocialities" making up the artwork itself, the qualities they have count as aesthetic qualities of the artwork itself. It may be useful to compare more traditional formal aesthetic qualities here: in nature and in non-artistic contexts, certain properties of proportionality or form may be beautiful and pleasing, and a work of art that creates or incorporates such properties can make it, the artwork, more beautiful and pleasing. Similarly, the fact that social aesthetics takes seriously that real social properties and relations are a part of the artwork itself allows it to treat the beauty of such relations as relevant to an evaluation of the artwork.

When we consider that EDI's typically non-hierarchical form of sociality reflects an ideal that we recognize as a social value in other realms, and is also atypical in many other institutions of dance creation and production, we are engaging the second and third planes of analysis. As we put it at one point in the previous section, the beauty of this sort of sociality is partly a function of our admiration and love for cooperative achievements of autonomous individuals in society more broadly (second plane). At the same time, it can model alternative social structures in the dance-institutional landscape and in society more broadly (third plane).

In both senses described above (that it is concerned with social relations immanent in the work itself, and that it is concerned with the relation between the artwork and the larger social context), social aesthetics treats the features of EDI made perspicuous by the collective action theory as aesthetically valuable. When we focus on the sort of social relations (at least typically) embodied in a good performance of EDI, we see that such a case is good not merely in being a clear case of collective action (though it is that), but also in being a good or valuable case of collective action. ${ }^{32}$ And its being socially good in this way is arguably not a mere extrinsic or moral feature of the artwork, but part of its aesthetic value. As "social relations can themselves get into, partake in, and animate aesthetic imagination and experience" (Born et al. 2017 pp. 2-3) we see that the value of EDI can be found at the nexus of its formal and social attributes. And we can also see the value of the work as a reflection of and/or potential influencer of social forms in artistic and social institutions.

\section{Conclusion}

We end with some questions for further research, suggested by our examination of the case of EDI: What might be the socio-political import of a collective act that

32 At least insofar as we value autonomy and freedom. 
prioritizes cooperation while keeping central the autonomy and freedom of individuals who participate? Do such forms merely reflect outlying social possibilities, or might they be modeling and generating new ones? What benefit might there be to collective acts that are also spontaneous, publicly displayed, and aesthetic or affective in nature? Much of the improvisation literature in dance theory (Buckwalter 2010; Foster 2002; Goldman 2010), but especially in jazz music theory (Fischlin, Ajay, and George 2013) stands at the crossroads of these questions.

In harmony with these and other discussions of improvisation in music and dance theory, our examination of EDI as a collective action suggests that it is rational to question received ideas about doing things together, especially assumptions that pre-planning and hierarchical structures, or mild forms of coercion, are necessary to do complex group activities, or that the expedience of these forms of collective action outweighs the values they sacrifice. It may be that, compared to the typically small-group format of ensemble improvisation, radically up-scaled groups and activities require more pre-packaged structures, roles, or recipes. Still, it seems rational to ask: just how much? It may be that activities with extremely high stakes or crucial goals cannot tolerate improvisation's openendedness. Though again, it seems reasonable to ask, in what cases or contexts might prioritizing the values elaborated here outweigh other kinds of achievement?

This is not to say that all planning is inevitably opposed to freedom and autonomy, or that improvisation is the only way to have open-ended planning and the possibility of rearranging unsatisfactory plans in ways that align with egalitarian ideals. In contexts where stakes are high and time is limited, democratic social practices might be preferable to improvisational process. But a collective process like the one in ensemble improvisation, with its rapid fluidity of roles, and its specific way of mutual listening and responsiveness, may be an additional model for open-ended or non-rigid structures of group interaction. Moreover, collective improvisation in the pursuit of demanding shared goals calls for more than respect for freedom; it demands active participation and skillful exercise of autonomy. At least in contexts where it would be valuable to accommodate a robust sharing of agency, the case of ensemble improvisation may provide a useful model.

Perhaps the kind of sociality that EDI practices could be translated for different contexts, taken up seriously or systematically so that theoretical and practical wisdom is mined and applied to socio-political challenges. This translation to other contexts might result in practical methods for effective cooperation in groups with diverse identities and perspectives. If so, such application could inform debates about the relation of individual freedom and communal responsibility, cooperation and competition, and contribute to innovation in matters of social justice. 
Acknowledgments: This work was completed with the support of research leaves from the University of Iowa, an Interdisciplinary Research Grant from the University of Iowa's Obermann Center for Advanced Studies, and a residency at the Center for the Advancement of Public Action (CAPA) at Bennington College (all in spring/summer 2019). We would like to thank Jovana Davidovic, Keith Harris and two anonymous referees of the journal for very helpful comments, and Susan Sgorbati (CAPA Director), Emily Climer, Marie Haas, and Penny Campbell for extensive discussion. We are also grateful to the faculty (Kathy Couch, Katherine Ferrier, Lisa Gonzales, Pam Vail) and students at MICI: Movement Intensive in Compositional Improvisation 2017 and 2018, where early versions were presented; and to the many other teachers, students, and peer practitioners in improvisation who have (and continue to) inspire serious inquiry into ensemble improvisation and its many social and aesthetic values, including Peter Schmitz, Terry Creach, Arthur Brooks, Michael Chorney, Ellie Goudie-Averill, Tori Lawrence, Anna Stark, Zach Bird, Brady Van Patten, Suzy Grant, Donnell Williams, Amanda Hamp, Ann Duffy, Joanna Futral, Lena Lauer, Katie Vason, Keely Walsh, Jason Palamara, and Justin Comer.

\section{References}

Albright, A. C., and D. Gere. 2003. Taken by Surprise: A Dance Improvisation Reader. Middletown, CT: Wesleyan University Press.

Alonso, F. M. 2018. "Reductive Views of Shared Intention." In Routledge Handbook of Collective Intentionality, edited by K. Ludwig, and M. Jankovic. New York, NY: Routledge.

Banes, S. 1994. Writing Dancing in the Age of Postmodernism. Middletown, CT: Wesleyan University Press.

Belgrad, D. 2016. "Improvisation, Democracy, and Feedback." In The Oxford Handbook of Critical Improvisation Studies, edited by G. Lewis, and B. Piekut. Chicago, IL: Oxford University Press.

Blom, L. A., and L. T. Chaplin. 1982. The Intimate Act of Choreography. Pittsburgh, PA: University of Pittsburgh Press.

Borgo, D. 2016. "The Ghost in the Music, or the Perspective of an Improvising Ant." In The Oxford Handbook of Critical Improvisation Studies, edited by G. E. Lewis, and B. Piekut. New York, NY: Oxford University Press.

Born, G. 2017 "After Relational Aesthetics: Improvised Music, the Social, and (Re)Theorizing the Aesthetic.” In Improvisation and Social Aesthetics, edited by G. Born, E. Lewis, and W. Straw. Durham, NC: Duke University Press.

Born, G. E., Lewis, and W. Straw, eds. 2017. Improvisation and Social Aesthetics, Duke University Press.

Bratman, M. E. 2014. Shared Agency: A Planning Theory of Acting Together. New York, NY: Oxford University Press.

Buckwalter, M. 2010. Composing while Dancing: An Improvisor's Companion. Madioson, WI: University of Wisconsin Press. 
Buss, S., and A. Westlund. 2018. "Personal Autonomy." In The Stanford Encyclopedia of Philosophy, edited by E. N Zalta. URL = https://plato.stanford.edu/archives/spr2018/ entries/personal-autonomy/.

Clarke, E. F., and M. Doffman. 2017. Distributed Creativity: Collaboration and Improvisation in Contemporary Music. New York, NY: Oxford University Press.

Fischlin, D., H. Ajay, and L. George. 2013. The Fierce Urgency of Now: Improvisation, Rights, and the Ethics of Cocreation. Durham, NC: Duke University Press.

Foster, S. L. 2002. Dances that Describe Themselves: The Improvised Choreography of Richard Bull. Middletown, CT: Wesleyan University Press.

Gilbert, M. 1989. On Social Facts. New York, NY: Routledge.

Goldman, D. 2010. I Want to Be Ready: Improvised Dance as a Practice of Freedom. Ann Arbor, MI: University of Michigan Press.

Hagberg, G. 2016. “Ensemble Improvisation, Collective Intention, and Group Attention.” In The Oxford Handbook of Critical Improvisation Studies, edited by G. E. Lewis, and B. Piekut. New York, NY: Oxford University Press.

Humphrey, D., and P. Barbara. 1959. The Art of Making Dances. Hightstown, NJ: Grove Press.

Kutz, C. 2000. "Acting Together." Philosophy and Phenomenological Research 61 (1): 1-31.

List, C., and P. Pettit. 2011. Group Agency: The Possibility, Design, and Status of Corporate Agents. New York, NY: Oxford University Press.

Ludwig, K. 2016. From Individual to Plural Agency (Collective Action: Vol. 1). New York: Oxford University Press.

Manin, B. 1987. “On Legitimacy and Political Deliberation.” Political Theory 15 (3): 338-68.

Marks, V. 2003. “Against Improvisation." In Taken by Surprise: A Dance Improvisation Reader, edited by A. Cooper Albright, and D. Gere, 135-9. Middletown, CT: Wesleyan University Press.

National Educational Television and Radio Center at Indiana University. 1966. "Bloomington." In Dance: Four Pioneers. Bloomington: Indiana University Audio-Visual Center.

Oshana, M. 2003. “How Much Should We Value Autonomy?" Social Philosophy and Policy 20 (2): 99-126.

Pateman, C. 1970. Participation and Democratic Theory. Cambridge, UK: Cambridge University Press.

Peter, F. 2017. "Political Legitimacy.” In The Stanford Encyclopedia of Philosophy (Summer 2017 Edition), edited by E. N. Zalta. URL = https://plato.stanford.edu/archives/sum2017/entries/ legitimacy/.

Pettit, P. 2012. On the People's Terms. Cambridge, UK: Cambridge University Press.

Pettit, P., and D. Schweikard. 2006. "Joint Actions and Group Agents." Philosophy of the Social Sciences 36 (1): 18-39.

Searle, J. 1990. "Collective Intentions and Actions." In Intentions in Communication, edited by P. Cohen, M. Pollack, and J. Morgan, 401-15. Cambridge, MA: MIT Press.

Sgorbati, S., C. Emily, and H. Marie. 2013. "Emergent Improvisation: On the Nature of Spontaneous Composition where Dance Meets Science." Contact Quarterly Dance and Improvisation Journal, Chapbook 438 (2).

The Architects. 2010. https://www.architectsdance.org/about (Accessed February 27, 2021). Tuomela, R. 2005. “We-Intentions Revisited.” Philosophical Studies 125 (3): 327-69.

Tuomela, R. 2018. "Non-reductive Views of Shared Intention." In The Routledge Handbook of Collective Intentionality, edited by K. Ludwig, and M. Jankovic. New York, NY: Routledge. Westlund, A. C. 2009. "Rethinking Relational Autonomy." Hypatia 24 (4): 26-49. 